14 | InterAção

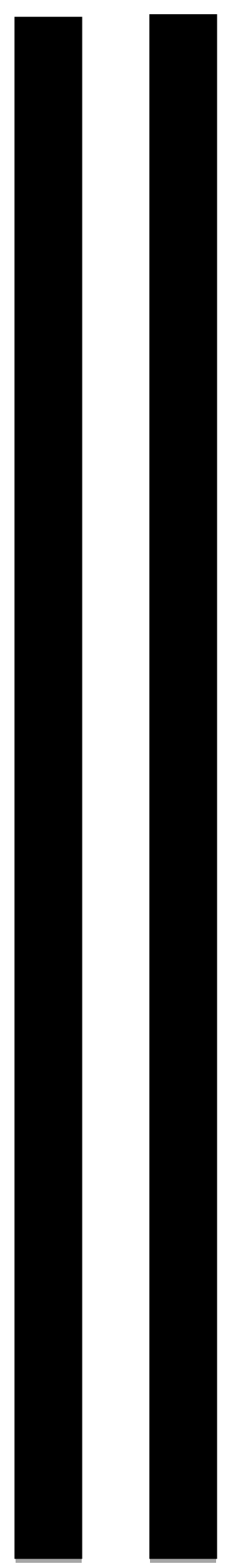

ARTIGOS 
15 InterAção

\title{
A SECURITIZAÇÃO POLÍTICO-ECONÔMICA NA AMÉRICA dO SUL E SEUS REFLEXOS NA ARGENTINA DURANTE O REGIME MILITAR (1976-1983)
}

\author{
Luciano Vaz Ferreira ${ }^{1}$ \\ Jahde de Almeida Lopez² \\ Vinicios Novelli Schulz ${ }^{3}$
}

\section{Resumo}

A proposta do presente artigo é investigar de que maneira ocorreu o processo de securitização (política e econômica) na América do Sul e seus reflexos na Argentina durante a sua última ditadura militar (entre 1976-1983). Trata-se de pesquisa exploratória e bibliográfica, que utiliza fontes interdisciplinares, nacionais e estrangeiras. Como resultados parciais da pesquisa, entende-se a possibilidade de aplicar as categorias da teoria da securitização no contexto da ditadura argentina, de modo a identificar o objeto referente, os atores securitizantes e o ato de fala capaz de definir a ameaça à segurança. A figura do inimigo interno, qualquer um que se manifestasse contra autoridade ou ideologia da ditadura, foi amplamente utilizada. É digno de nota a inclusão também do "subversivo econômico", qualquer um que representasse ameaça aos interesses econômicos da elite dirigente, incluindo empresas competidoras e integrantes do movimento sindical, que foram duramente reprimidos em ações conjuntas entre as forças de segurança e parte do setor empresarial colaboracionista.

Palavras-chave: Securitização. Guerra Fria. América do Sul. Argentina. Regime Militar.

\begin{abstract}
The purpose of this article is to investigate how it happened the process of securitization (political and economic) in South America and its repercussions in Argentina during its last military dictatorship (1976-1983). This is exploratory and bibliographical research, which uses interdisciplinary sources, both national and foreign. As partial results of the research, it
\end{abstract}

1 Doutor em Estudos Estratégicos Internacionais pela Universidade Federal do Rio Grande do Sul (UFRGS), com pesquisa na American University (Washington, D.C.). Professor Adjunto do Curso de Graduação em Relações Internacionais da Universidade Federal do Rio Grande (FURG). Professor Permanente do Mestrado em Direito e Justiça Social (FURG).

2 Graduanda em Relações Internacionais pela Universidade Federal do Rio Grande (FURG). Bolsista de iniciação científica da FAPERGS.

3 Graduando em Relações Internacionais pela Universidade Federal do Rio Grande (FURG). Bolsista de iniciação científica da FURG.

Revista InterAção, v. 8, n. 2, jul/dez 2017

ISSN 2357-7975 
16 | InterAção

is the possibility of using the categories of securitization theory in the context of the Argentine dictatorship, in order to identify the referent object, securitizing actors and the speech act capable of defining the security threat. The figure of the internal enemy, anyone who manifested itself against the authority or ideology of the dictatorship, was widely used. Also noteworthy is the inclusion of the "economic subversive", any one who poses a threat to the economic interests of the ruling elite, including competing companies and members of the trade union movement, who have been harshly repressed in joint actions between security forces and part of the business sector.

Keywords: Securitization. Cold War. South America. Argentina. Military Dictatorship.

\section{INTRODUÇÃO}

Um dos períodos mais marcantes da história compartilhada da América do Sul diz respeito aos regimes autoritários instaurados no decorrer do século XX durante a Guerra Fria. Experiência caracterizada por graves violações de Direitos Humanos, deixou um legado indelével que pode ser sentido até hoje, representada tanto na configuração das instituições destes países (muitas ainda de viés autoritário), na dificuldade política em implementar uma democracia de indiscutível estabilidade e na perpetuação de dinâmicas econômicas de natureza ainda "prémoderna". Apesar da dificuldade em lidar com essas "veias abertas" ser a tônica na região, a experiência argentina tem se destacado, especialmente pelo engajamento representado pela sociedade civil após o processo de democratização, que gerou várias investigações contra aqueles que participaram ativamente ou colaboraram com o regime autoritário.

A proposta do presente artigo é investigar a questão sob a ótica das relações internacionais, com foco nos estudos de segurança, um campo ainda emergente no cenário sul-americano. Neste sentido, elegeu-se como base científica a "teoria da securitização", trabalhada pela "Escola de Copenhague", representada pelos escritos de Barry Buzan, Ole Weaver e Jaap de Wilde na obra Security: A New Framework for Analysis, publicada em 1998.

A pesquisa possui como problema analisar de que maneira ocorreu o processo de securitização (política e econômica) na América do Sul e seus reflexos na 
17 InterAção

Argentina durante a sua última ditadura militar (entre 1976 e 1983). A escolha pela Argentina foi justamente pelo caráter emblemático que sua experiência representa na região, que redundou em maior quantidade de registros e pesquisas na área, principalmente no que diz respeito à dimensão econômica da questão, muitas vezes esquecida. A investigação possui natureza exploratória, não excluindo novas incursões acadêmicas no futuro. Nesse passo, optou-se de forma preliminar por uma pesquisa de caráter bibliográfico, utilizando-se fontes interdisciplinares, nacionais e estrangeiras.

$\mathrm{O}$ artigo apresenta-se em duas partes. A primeira trata do processo de securitização da América do Sul ocorrido durante a Guerra Fria, englobando uma breve apresentação da "teoria da securitização", a contextualização internacional do mundo bipolar, o surgimento e o conteúdo da doutrina de segurança nacional e a análise da securitização política e econômica na região. Na segunda parte o foco será no processo de securitização do regime ditatorial argentino (1976-1983), apresentando a contextualização local do golpe militar e investigando uma possível aplicação da "teoria da securitização" no caso argentino, com foco nas dinâmicas políticas e econômicas.

\section{A SECURITIZAÇÃO DA AMÉRICA DO SUL DURANTE A GUERRA FRIA}

Já se passaram mais de duas décadas desde que a chamada "Escola de Copenhague", na qual se destacam Barry Buzan, Ole Waever e Jaap de Wilde, propôs rediscutir o conceito de segurança nas relações internacionais. Em linhas gerais, segurança é relacionada à sobrevivência de algo. Há uma ameaça à segurança quando um problema torna-se uma ameaça existencial a um determinado objeto (geralmente, mas não exclusivamente, um Estado, governo, território ou uma sociedade). A natureza especial da segurança justifica o uso de medidas extraordinárias para lidar com um determinado problema. Tradicionalmente restrito à análise dos conflitos militares em uma perspectiva estadocêntrica, Buzan, Weaver e 
18 InterAção

Wilde propõem a possibilidade de ampliação destes estudos, de modo a abranger além das questões militares, os aspectos políticos, econômicos, ambientais e sociais da segurança, incluindo nesta dinâmica também a participação dos atores nãoestatais (BUZAN; WAEVER; WILDE, 1998, p. 07-08; 21).

Um aspecto chave para os estudos de segurança são os chamados processos de "securitização". "Securitização" é uma variante extrema da "politização" de um problema. Em teoria, qualquer problema público pode ser enquadrado como "não politizado", significando que o Estado opta por não lidar com o problema, não tornando objeto de debate e decisões públicas. Será "politizado", quando o problema é incluído nas políticas públicas, necessitando de decisão governamental e alocação de recursos. Por fim, enquadra-se em "securitizado", quando o problema é apresentado como uma ameaça existencial, requerendo medidas de emergência e justificando ações fora dos limites normais da política (BUZAN; WEAVER; WILDE, 1998, p. 23-24).

Três tipos de unidades fazem parte da análise do processo de securitização: objetos referentes (referent objects): algo que é ameaçado e possui legitimidade de clamar sobrevivência; atores securitizantes (securitizing actors), atores que securitizam problema declarando que algo está existencialmente ameaçado; e atores funcionais (functional actors) que influenciam decisões no setor da segurança (BUZAN; WAEVER; WILDE, 1998, p. 36).

Um aspecto importante diz respeito à percepção da segurança como uma prática autorreferencial e socialmente constituída. Um problema é considerado como uma ameaça de segurança não por que realmente existe, mas por que a questão é apresentada como uma ameaça (BUZAN; WEAVER; WILDE, 1998, p. 24). A segurança é definida por um "ato de fala" (speech act). A fala possui o efeito de dar foco a um problema específico, implicando que todos os meios necessários serão utilizados para neutralizar a ameaça. Uma vez que os detentores do poder, a elite dirigente, estabelecem um problema de segurança e a audiência passa aceitar esse fato, a securitização acontece (WEAVER, 1995, p. 56). 
19 | InterAção

Neste contexto, qualquer questão pode ser securitizada. A agenda de segurança não envolve apenas a proteção do Estado ou do governo contra ataque externo (como a invasão de um Estado inimigo), mas também o uso da força contra ameaças não militares. Qualquer movimento que possa questionar a autoridade governamental é vulnerável à securitização, tornando-se instrumento para a elite dirigente consolidar a sua legitimidade doméstica e internacional (BUZAN; WEAVER; WILDE, 1998, p. 22; 51-54). Aqui, os aspectos militares, políticos, econômicos, ambientais e sociais se entrelaçam, de modo a formar objetos de segurança tão díspares como terrorismo, crime organizado, fluxo migratórios (FERREIRA, 2011), proteção da economia nacional, meio ambiente, religião, cultura e ideologia.

Realizadas as necessárias considerações de natureza teórica, parte-se para o estudo dos processos de securitização na América do Sul. A região, objeto da pesquisa, experimentou um influxo de processos entre as décadas de 50 e 90 do século $X X$, que marcou definitivamente sua história. Apresentam-se como principais fatores para a securitização da América do Sul neste período: o primeiro, de natureza externa, referente à conjuntura internacional marcada pela bipolaridade da Guerra Fria; e o segundo, de natureza interna, que diz respeito ao agravamento da crise econômica e social da região, o crescimento da polarização política e a resistência de uma elite dirigente em realizar reformas necessárias para a modernização destes Estados (tal como reforma agrária e consolidação do Estado de Bem Estar Social), visando manter seu status quo.

No cenário pós-1945, emergiu a disputa bipolar entre os Estados Unidos e a União Soviética (URSS), que representavam modelos políticos e econômicos antagônicos. Desde as primeiras análises de conjuntura realizadas por estudiosos norte-americanos, a URSS foi vista como uma ameaça expansionista, fruto da necessidade de projeção internacional do modelo marxista. Neste cenário, a diplomacia norte-americana passou a defender uma "política de contenção", que consistia em bloquear os avanços da URSS em qualquer local do mundo, utilizandose de todos os meios necessários. Isto implicava não somente uma reação militar, mas 


\section{0 | InterAção}

uma interferência política e econômica para impedir que determinados países se transformassem em possíveis aliados à URSS (KENNAN, 1947, p. 574).

Um dos aspectos centrais desta estratégia é o desenvolvimento da “doutrina de segurança nacional", criada pelos EUA no início da Guerra Fria. O objetivo de tal doutrina é difundir a ideia de caracterização da URSS como uma ameaça à segurança nacional dos EUA, em uma concepção ambígua que abrangia não somente a proteção a um possível ataque ao território norte-americano e de seus aliados, mas a defesa do modelo econômico capitalista e do american way of life. A doutrina é muito influenciada pela geopolítica, que estuda a relação entre a geografia e os Estados com objetivo de conceder sucedâneos às decisões políticas e estratégicas (COMBLIN, 1978, p. 25). A influência da geopolítica implica na ideia de que a proximidade geográfica ocasionaria a necessidade de um alinhamento automático de todos os países do continente americano em torno dos EUA, devendo ser repelida a interferência exógena (COUTO E SILVA, 1967, p. 52).

Desde as primeiras décadas da sua independência, os EUA já se preocupavam em manter o continente americano sob o seu controle, livre de influências externas, como era definido por meio da Doutrina Monroe ("América para os americanos"), ainda no séc. XIX. A realização da Conferência Pan-Americana (que posteriormente deu origem a Organização dos Estados Americanos) e o Tratado Interamericano de Assistência Mútua (TIAR), com objetivo de promover a defesa hemisférica, comprovam tal afirmação. A aproximação de Cuba com a URSS pós-revolução (1959) e a crise surgida do processo de implantação de mísseis soviéticos na ilha (1962), fizeram com que os EUA redobrassem suas atenções e energia à América Latina (e, consequentemente, à América do Sul) (BUITRAGO, 2002, p. 08-11). Sob a ótica do governo norte-americano, era necessário agir para que os Estados vizinhos mantivessem governos simpáticos aos EUA.

Além do suporte logístico e econômico dado pelos EUA, houve uma inegável influência ideológica nas elites responsáveis por desencadearem os golpes de Estado e a instauração de regimes autoritários. Um dos exemplos consiste na inserção da doutrina da segurança nacional na formação educacional de vários militares latino- 
21 InterAção

americanos, que participaram de cursos fornecidos pelo governo norte-americano, especialmente no programa da U.S. Army School of Americas, com sede no Panamá (BUITRAGO, 2002, p. 07) Muitos destes militares acabaram por ocupar posições importantes nos comandos de suas forças armadas nacionais e teriam contribuído nos vindouros golpes de Estado (SCHOOL OF AMERICAS WATCH, 2015).

O resultado deste processo foi a instalação de várias ditaduras militares na América do Sul, incluindo Bolívia (1971-1985), Brasil (1964-1985), Chile (1973-1990), Colômbia (1953-1957), Equador (1972-1979), Paraguai (1954-1989), Suriname (19801988), Uruguai (1973-1984) e Argentina (em três momentos, 1955-1958; 1966-1973; e 1976-1983). Apesar das diferenças particulares dos contextos locais, é possível traçar pontos em comum entre os regimes, que incluem a dissolução de instituições representativas, falência ou crise aguda dos regimes e partidos políticos tradicionais, e securitização da vida política e econômica (COGGIOLA, 2001, p. 11).

Buzan, Weaver e Wilde (1998, p. 22) caracterizam um processo de securitização política quando lida com ameaças que desafiam a soberania ou a ideologia que constitui um Estado. Neste contexto, a soberania poderia ser ameaçada por qualquer coisa que questiona o seu reconhecimento, legitimidade ou autoridade governamental. Um aspecto central deste tipo de securitização é a criação da figura do "inimigo", um conceito clássico presente na literatura de Carl Schmitt e publicado em 1926. De acordo com o autor, a distinção entre "inimigo" e "amigo" é um aspecto central do fenômeno político, representando o grau extremo de intensidade de uma união ou separação. É a partir dessa associação ou desassociação que é possível garantir a unidade política. O "inimigo" é o "diferente", o "desconhecido", cujos conflitos não podem ser resolvidos dentro da normalidade e que deve ser combatido (SCHMITT, 2009, p. 27-28). O inimigo pode ser "externo", quando a possibilidade de guerra envolve unidades políticas organizadas diferentes (Estados), ou "internos", quando o combate armado ocorre no interior de uma unidade organizada (SCHMITT, 2009, p. 34). Assim como para "Escola de Copenhague" os atores de securitização são os responsáveis por definir a ameaça de segurança, para Schmitt é o 
próprio Estado que define quem são os seus inimigos, independentemente de qualquer juízo moral.

No que diz respeito às ditaduras da América do Sul e a securitização da política, também houve a criação da figura do "inimigo". Nestes regimes, o "inimigo externo" correspondia à ameaça militar tradicional, uma possível invasão das forças armadas soviéticas e de seus aliados. Já o "inimigo interno", era o "subversivo", não apenas os que possuíam simpatia pelo projeto comunista, mas todos aqueles que contestassem de qualquer forma a ideologia e a legitimidade do governo autoritário. Ambos inimigos estavam sujeitos às medidas de exceção (como toda a ameaça de segurança), o que na prática transformou-se em detenções arbitrárias, desaparecimentos forçados, prática de tortura e a suspensão de direitos civis e políticos básicos, como a liberdade de expressão (BUITRAGO, 2002, p. 18).

Outro processo de securitização presente na América do Sul pode ser caracterizada como econômica. A participação dos agentes econômicos nos regimes autoritários e nos processos de securitização é um aspecto pouco estudado, apesar da inegável influência destes atores (ARBOUR, 2007, p. 05; SHARP, 2012, p. 782). De acordo com Buzan, Weaver e Wilde (1998, p. 22), a securitização econômica liga-se diretamente às atividades empresárias e diz respeito ao uso de medidas extraordinárias com objetivo de proteger a ordem econômica e seus atores (como as empresas no sistema capitalista) de uma ameaça existencial.

A adoção de um modelo comunista significaria a reorganização dos fatores de produção, o que implicaria na derrocada do projeto capitalista e da elite econômica atrelada a esta dinâmica. Sendo assim, no contexto de securitização, o manejo da economia nacional comportou medidas extraordinárias de rápida aplicação, que incluíam o abruto corte de despesas governamentais, especialmente em políticas sociais, como saúde e educação, a privatização de setores sensíveis de interesse nacional, e a abertura de capital para o investimento estrangeiro. Os gastos militares e com os aparatos de repressão, em contrapartida foram ampliados sobremaneira, apesar dos cortes (COGGIOLA, 2001, p. 38-39). 
23 | InterAção

O binômio repressão política aliada à liberalização econômica, implementado nas ditaduras da América do Sul, foi chamada de "terapia do choque", por Naomi Klein (2007). Nesta estratégia, há primeiro um choque proporcionado pela aplicação sistemática da violência estatal, por meio de detenções arbitrárias e desaparecimentos, de modo a instar medo e neutralizar possíveis resistências, depois, implementa-se uma nova política econômica, em harmonia com os interesses do capital internacional. Na prática, a América do Sul virou um grande laboratório para a experimentação de preceitos neoliberais (inclusive em uma variante extremada), que colaborou para o desmonte das políticas de proteção social, destruição da indústria nacional e agravamento das desigualdades econômicas e sociais na região. Quando alguns dos países voltaram-se tardiamente para uma tentativa de nacionalismo econômico, investiu-se em obras de infraestrutura gigantescas e pouco eficientes, que produziram maior endividamento externo (financiado por bancos estrangeiros) e em empresas nacionais cujos donos possuíam algum tipo de relação estreita e subterrânea com as esferas de poder.

\section{A SECURITIZAÇÃO NA ARGENTINA DURANTE O REGIME MILITAR (1976-1983)}

No auge da Guerra Fria, a Argentina foi palco de vários golpes de Estado (1955, 1966 e 1976) com a participação ativa dos militares, responsáveis por desencadear processos de securitização (COGGIOLA, 2001, p. 17-20; 27-29). Como a pesquisa não se trata de uma análise da história política argentina, opta-se por concentrar a contextualização na experiência da ditadura civil-militar ocorrida entre o período de 1976 a 1983, a mais recente e que antecede o novo período democrático.

A política econômica do governo do General Onganía (1966-1970) conduzida por Adalbert Kriger Vasena, que advinha de uma poderosa família de industriais e também era diretor de várias filiais norte-americanas na Argentina, foi responsável por agravar a crise político-econômica do país. O período foi marcado pela diminuição dos direitos sociais, desemprego e superexploração da mão de obra. 
24 | InterAção

Como resultado, o movimento sindical passou a reagir e revindicar mudanças, por meio de greves e manifestações públicas, destacando-se os operários de Córdoba, que sofriam com drástico aumento de jornada e redução de salários decretados pelo governo para compensar a crise do setor automobilístico. Frente a esse contexto de polarização política, surgem os primeiros grupos armados de contestação ao governo, que passam à prática da guerrilha (COGGIOLA, 2001, p. 18). A mudança de generais na presidência e a implementação de uma política econômica nacionalista não foi suficiente para manter a ditadura, abrindo-se novamente a possibilidade de eleições.

Com o fim do regime, Juan Domingo Perón, figura populista e uma grande liderança argentina, que já tinha sido presidente em dois mandatos (1946-1955) e que se encontrava em exílio após os golpes miliares, volta à cena política. Inicialmente impedido de concorrer na primeira eleição, acaba por ser vitorioso na eleição seguinte, em 1973. Perón apresentava-se com uma plataforma política de aliança nacional, com objetivo de congregar a direita e a esquerda, e pacificar o movimento operário (CRENZEL, 2016, p. 41). Não conseguiu, contudo, agradar nenhum dos lados em uma Argentina que já cambaleava com a Crise do Petróleo e o radicalismo político. Indícios apontam ligações de um secretário pessoal de Perón com organizações paramilitares anticomunistas, o que acaba por desmitificar a sua figura política como sendo estritamente ligado à causa social (COGGIOLA, 2001, p. 46).

Com a morte de Perón em 1974 e a ascensão de sua esposa, Maria Estela Martínez de Perón, que exercia o mandato de vice-presidente, o governo argentino guinou definitivamente para a extrema direita. O governo de Isabelita Perón passou a perseguir ferozmente grupos de orientação comunista e sindicatos, por meio de "decretos de aniquilamento", direcionados à autorização para as forças armadas neutralizarem indivíduos considerados como "subversivos", estabelecendo prisões clandestinas e execuções extrajudiciais (COGGIOLA, 2001, p. 47).

Detendo plenos poderes para as suas operações, as forças militares ganharam poder e confiança para realizar um novo golpe de Estado e assumir o poder. À época, apenas a Argentina era o país que não possuía um governo militar no Cone Sul. O 
golpe argentino fundamentou-se ideologicamente na doutrina de segurança nacional, no integralismo católico e no anticomunismo, servindo-se do terror de Estado (RAMPINELLI, 2012, p. 356).

No dia 24 de março de 1976, uma junta militar formada toma controle do governo. A mudança política foi chamada de "Processo de Reorganização Nacional" e apresentada como uma resposta a uma "percepção generalizada de crise e desordem da nação argentina" (BARROS, 2009, p. 81). O general Jorge Rafaela Videla, oriundo do exército, passou a exercer a presidência.

O novo regime ditatorial desencadeou um processo de securitização, que causou reflexos nos setores políticos e econômicos, como aconteceu em outras ditaduras da América do Sul durante a Guerra Fria. A “doutrina de segurança nacional" foi também disseminada na Argentina por meio de instrutores militares e de inteligência estrangeiros, que ministravam cursos de formação nas forças armadas nacionais (TAIANA, 2016, p. 61). Neste contexto, tomando com base a teoria de Buzan, Weaver e Wilde, o objeto referente, o que estaria ameaçado e possui legitimidade para clamar sobrevivência, é o próprio Estado argentino, especialmente o seu projeto ideológico, político e econômico pós-golpe. Os atores securitizantes, responsáveis por securitizar o problema declarando que objeto referente está ameaçado, foi o setor militar, que tomou o poder após o golpe de 76, aliado à elite política e econômica, apoiadora da instauração de um regime autoritário protetor de seus interesses.

Como comentado anteriormente, a segurança é definida como um "ato de fala", em que a elite dirigente estabelece que aquele problema necessita ser enfrentado com medidas extraordinárias, com aceitação de uma audiência. Sendo assim a ameaça não precisa ser real, podendo, basta ser declarada desta maneira por um ator securitizante. No caso argentino, este acontecimento é facilmente identificado a partir de uma breve análise de alguns discursos proferidos pelo presidente Videla logo após o golpe. É declarada uma "guerra" contra os "subversivos", categoria que se enquadra na figura do "inimigo interno" de Schmitt. Em discurso proferido em 12 de maio de 1976, frente a imprensa argentina, Videla 
afirmou que a "subversão não é somente uma manifestação objetiva de um grupo armado [...] é um fenômeno mais complexo, profundo, global, onde estão justamente em jogo os valores subvertidos." Em discurso de 30 de junho de 1976 em Buenos Aires declarou que objetivo do "Processo de Reorganização Nacional" é o "aniquilamento da subversão em todas as suas manifestações". Por fim, Videla afirmou frente a imprensa argentina em 8 de setembro de 1976 que a luta contra a "subversão" "não se esgota puramente em um problema de escala militar", uma vez que se trata de um fenômeno de dimensão política, econômica, social, cultural, psicológica e militar (VIDELA, 1976).

A recepção da audiência do "ato de fala" de securitização também pode ser encontrado. Diversos segmentos sociais, como a Igreja Católica, partidos políticos, sindicatos, meios de comunicação (BARROS, 2009, p. 85) e parte do setor empresarial rapidamente se identificaram com as condições do novo regime, passando a apoiá-lo. Apesar do repetido anúncio de um conflito contínuo, não havia guerra civil na Argentina: a guerrilha, localizada territorialmente, havia sido praticamente eliminada em 1976. A subversão tornou-se qualquer ação social ou individual que fosse contra o governo (COGGIOLA, 2001, p. 56), o que reforça a ideia de securitização da política. Como resultado desta securitização, o governo argentino apesar das tentativas de aparentar normalidade, promoveu um verdadeiro “terrorismo de Estado" (BASSIOUNI, 2000, p. 84), que incluiu o exílio forçado, a censura, perda de direitos civis, tortura e eliminação de adversários políticos (DUHALDE, 2013, p. 19). Estima-se que entre 10.000 e 30.000 pessoas desapareceram durante a ditadura (1976-1983). Mais de 1 milhão de argentinos foram para o exílio (CONADEP, 1984).

No que diz respeito à securitização econômica na Argentina, algumas observações devem ser feitas. A securitização da economia serviu claramente para reforçar o aparato repressivo e beneficiar economicamente os apoiadores do golpe, estabelecendo um plano econômico que fosse favorável à elite dominante. Durante o período democrático, o país encaminhava-se para uma melhora no bem estar social, porém, com a instauração da ditadura em 1976, todos os projetos foram abandonados 
27 | InterAção

(HEREDIA, 2016, p. 47). O novo regime eliminou os direitos sociais conquistados em décadas de lutas pelos trabalhadores argentinos, que incluíam o direito de greve e de negociação sindical (BASUALDO, 2016, p. 83). Entre o período de 1976 a 1982, o número de trabalhadores empregados nas indústrias caiu 36,7\%, mantendo-se a mesma produtividade, o que representa jornadas extenuantes (RECALDE, 2016, p. 219).

A política econômica do Ministro Martínez de Hoz promoveu a liberalização econômica para atrair capital estrangeiro, focando-se apenas no investimento em produção primária (agricultura, mineração e petróleo) e abandonando o processo de industrialização. A economia foi reduzida a oligopólios, principalmente controlados por empresas estrangeiras, eliminando-se qualquer tipo de competitividade (SCHORR, 2016, p. 235).

Partiu-se para uma série de financiamentos, de bancos estrangeiros e do Fundo Monetário Internacional, com objetivo de tentar estabilizar a economia argentina e apresentar normalidade, apesar da grave crise que enfrentava. O dinheiro acabou por financiar o aparato de repressão e segurança do governo argentino (BOHOSLAVSKY, 2016, p. 110). O resultado a longo prazo do sucateamento da economia argentina e a total ausência de desenvolvimento social acarretaram recessão, marcada pela alta inflação, desemprego e endividamento externo.

Como resultado da securitização da economia, as atividades empresárias foram completamente afetadas por esta dinâmica. Durante a ditadura, foi criada a "Comissão Nacional de Responsabilidade Patrimonial" (CONAREPA), com a atribuição “identificar indivíduos responsáveis por causar danos aos interesses da nação", "proibindo indivíduos e empresas de administrar e dispor de sua propriedade". Apresentado como um órgão do Estado com objetivo de zelar pela modernização econômica e administrativa, converteu-se em instrumento de perseguição e expropriação de bens de empresários que eram contrários ao regime (DELGADO, 2016, p. 276). As empresas de imprensa foram as grandes atingidas, passando a sofrer intervenções governamentais e afastamento de seus diretores, bem como a venda forçada de suas ações a outras empresas, cujos donos eram apoiadores 
da ditadura (GUALDE, 2016; LORETI, 2016).

De forma semelhante aconteceu com a Comissão Nacional de Valores (CNV), que possui a atribuição de regular o mercado de ações, tendo sido transformado durante o regime em órgão de inteligencia. Os potenciais concorrentes comerciais dos grandes conglomerados (e apoiadores da ditadura) eram duramente perseguidos pela força de segurança (chamados de "subversivos econômicos"), graças a informações compartilhadas pela CNV (DANDAN, 2016, p. 278).

Um capítulo importante e nefasto da história argentina foi a estreita colaboração de certos agentes econômicos e o aparato de segurança e repressão. Existem vários registros da participação direta de empresas (nacionais e estrangeiras) no desaparecimento e tortura de seus funcionários. Aqui, na linha dos escritos de Buzan, Weaver e Wilde, as empresas podem ter atuado como atores funcionais da securitização, influenciando e beneficiando-se do processo desencadeado pelos setores militares. Apesar deste não ser um rol exaustivo, os principais casos de estreita colaboração entre as forças de segurança e as empresas e que podem ser encontrados na bibliografia especializada são os seguintes: Antarsa, Acindar, Dálmine Siderca, Ledesma, Ford Motors e Mercedes-Benz.

A Antarsa era uma empresa de metalurgia de Tigre, Argentina. No início da década de 70, um grupo de trabalhadores começou a se organizar para contestar as precárias condições de trabalho que geravam acidentes frequentes. Logo após o golpe de 1976, a empresa foi ocupada por militares, que prendeu 60 operários com a colaboração da empresa, responsável por fornecer a lista dos trabalhadores (FILIPPINI; CAVANA, 2011, p. 321). Houve inclusive pagamentos extra por parte da empresa para que as forças de segurança agissem na repressão dos sindicalistas e defendessem os interesses empresariais. Entre os presos, 16 permanecem desaparecidos até hoje (BASUALDO, 2006, p. 02).

A Acindar também trabalhava no ramo metalúrgico, em Rosário. Sob a alegação de abrigar conspiradores, suas fábricas foram ocupadas pela polícia e forças militares em 1975. Em pouco tempo a Acindar tornou-se uma espécie de quartel 
29 | InterAção

general para operações de repressão, na qual as forças de segurança residiam permanentemente, com o consentimento dos executivos da empresa (BASUALDO, 2006, p. 06). O estabelecimento foi transformado em um centro clandestino de detenção (FILIPPINI; CAVANA, 2011, p. 333). Centenas de trabalhadores ligados ao movimento sindical foram demitidos e cerca de 300 pessoas foram detidas. Um dos presidentes da empresa foi convidado para exercer o cargo de Ministro da Economia durante a ditadura, aproveitando-se da posição influente para beneficiar a sua companhia (PAULÓN, 2016, p. 177).

Assim como as anteriores, a Dálmine Siderca também era uma empresa da área da metalurgia, situada em Capana. Da mesma forma, colaborou com as forças de segurança fornecendo listas de funcionários ditos "subversivos", geralmente ligados aos movimentos sindicais (BASUALDO, 2006, p. 06-07).

A Ledesma é uma empresa de agronegócios ainda em funcionamento, que à época possuía uma usina de cana de açúcar em Jujuy. Como se trata de um lugar afastado dos grandes centros populacionais, costumava a oferecer residência e demais estruturas de habitação aos seus funcionários, criando uma pequena cidade. Esta condição, contudo, com a instauração da ditadura militar, tornou-se um ambiente de monitoramento do comportamento dos funcionários, seja em atividades políticas contra o governo ou a Ledesma. O grau de securitização foi tamanho que a segurança privada da empresa atuava em conjunto com as forças oficiais, misturando-se a cadeia de comando, sendo difícil individualizar a conduta de cada grupo (DANDAN; FRANZKI, 2016, p. 192). Um fato emblemático foi a "Noite do Apagão", ocorrido em julho de 1976, logo após o golpe militar. Na ocasião a Ledesma teria desligado deliberadamente o fornecimento de energia elétrica, de modo a facilitar uma operação militar que prendeu mais de 400 pessoas, entre sindicalistas, ativistas políticos e estudantes (PAYNE; PEREIRA, 2016, p. 40).

O caso da Ford Motors, montadora de automóveis norte-americana, é emblemático por se tratar de uma empresa estrangeira. Além do monitoramento e perseguição de seus funcionários, a colaboração da Ford envolveu a criação de um quartel general e centro de detenção e tortura clandestino nas dependências da 
30 | InterAção

própria empresa. Também é digno de nota o apoio logístico oferecido pela Ford, com a cedência de seus automóveis para que as forças de segurança fizessem operações de repressão por toda a Argentina. Em contrapartida, a Ford beneficiou-se com as políticas neoliberais de diminuição dos direitos trabalhistas, com a venda de seus carros ao governo (vendidos em preços acima de 10 vezes o valor de mercado) e da constante vigilância do exército dentro de suas fábricas, que impedia os seus funcionários de realizarem greve, apesar das condições de trabalho indignas (QUINTANA; BASUALDO VARSKY, 2016, p. 159-165).

Também uma empresa estrangeira automotiva, a alemã Mercedes-Benz tem sido citada como colaboracionista. Aqui também são relatados trocas de informações de inteligencia entre a empresa e o governo, demissões em massa e detenções arbitrárias de funcionários em suas dependências. $\mathrm{O}$ exército argentino tornou-se o maior cliente na compra de seus veículos (BASUALDO, 2006, p. 14).

O que se observa, a partir dos registros de colaboracionismo entre as empresas (estrangeiras e argentinas) e o governo autoritário, é uma espécie de securitização da dinâmica empresarial. Os sindicalistas presos, torturados e executados não eram apenas adversários políticos do regime, enquadrados como os "inimigos internos", mas também vistos como uma ameaça para as corporações em questão, pois revindicavam justamente melhores condições de trabalho, frente as jornadas extenuantes, ambiente propício a doenças e acidentes e baixos salários. Neste contexto, como resultado da securitização, as linhas que separam a política, economia e a segurança tornaram-se ainda mais tênues, pois o inimigo declarado (ou criado pelo “ato de fala") é ao mesmo tempo um inimigo político e econômico.

\section{CONSIDERAÇÕES FINAIS}

A "Escola de Copenhague" introduz uma nova abordagem para os estudos de segurança, colocando como objeto de discussão os processos de securitização. Nesta linha, a segurança é vista como uma prática socialmente construída. Logo, uma Revista InterAção, v. 8, n. 2, jul/dez 2017 
31 InterAção

ameaça de segurança não precisa realmente existir, sendo definida por um "ato de fala" e aceitação da audiência, legitimando, em tese, o uso de medidas extraordinárias. Isto dignifica que sob o ponto de vista teórico qualquer problema é suscetível de ser securitizado, incluindo questões de natureza política e econômica.

A partir da instauração de regimes autoritários na América do Sul durante a Guerra Fria, a região passou a ser objeto de processos de securitização. A disseminação da chamada "doutrina da segurança nacional" pelos EUA foi determinante neste projeto, congregando dimensões militar, política e econômica. A securitização política nos regime ditatoriais na América do Sul é marcada pela criação da figura do "inimigo interno", à la Schmitt, considerado todo aquele que contesta a ideologia ou legitimidade do governo autoritário. Nesta lógica, o "subversivo" deveria ser perseguido e neutralizado. A ameaça à segurança também foi utilizada para justificar uma série de medidas extraordinárias (de natureza neoliberal) no campo econômico, que implicaram na redução dos gastos em políticas sociais, sucateamento da indústria nacional e agravamento da desigualdade econômica e social.

O enredo sul-americano de golpismo e securitização também foi replicado na Argentina. Durante o chamado "Processo de Reorganização Nacional" foi instaurada uma ditadura, que foi mantida entre 1976 e 1983. A partir da pesquisa, entende ser possível a utilização das categorias apresentadas pela "Escola de Copenhague" no estudo da securitização da Argentina durante o período ditatorial, entendendo-se como o objeto referente o próprio Estado argentino e como ator securitizante o setor militar, aliado à elite político-econômica. O dito "ato de fala", que cria a ameaça de segurança (não necessariamente real) pode ser facilmente encontrado em diversos discursos oficiais do governo.

Assim como em outros países da América do Sul, o inimigo interno era o "subversivo", não apenas quem simpatizasse com a ideologia marxista, mas que fizesse qualquer manifestação contra a autoridade ou ideologia da ditadura argentina. O processo de securitização da economia serviu para reforçar o aparato repressivo e beneficiar economicamente os apoiadores do golpe, estabelecendo um 
32 InterAção

plano econômico que levou a Argentina a ruínas. A partir dali, criou-se a figura do "subversivo econômico", qualquer um que representasse uma ameaça aos interesses econômicos da elite dirigente, incluindo empresas competidoras e integrantes do movimento sindical. Isto fica claro na análise de alguns casos em que se comprova uma estrita colaboração entre o regime ditatorial e parte do setor empresário (nacional e estrangeiro).

\section{REFERÊNCIAS}

ARBOUR, Louise. Economic And Social Justice for Societies in Transition. New York University Journal of International Law and Politics, New York, v. 40, p. 1-27, 2007.

BARROS, Mercedes. M. El Silencio Bajo la Última Dictadura Militar en la Argentina. Pensamento Plural, Pelotas, v. 5, p. 70-101, 2009.

BASSIOUNI, M. Cherif. Legal Control of International Terrorism: A Policy-Oriented Assessment. Harvard International Law Journal, Cambridge, v. 43, p. 82-95, 2000.

BASUALDO, Eduardo M. The Legacy of Dictatorship: The New Pattern of Capital Accumulation, Deindustrialization, and the Decline of the Working Class. In: BOHOSLAVSKY, Juan Pablo; VERBITSKY, Horácio (Org.). The Economic Accomplices to the Argentine Dictatorship: Outstanding Debts. New York, Cambridge University Press, 2016, p. 75-89.

BASUALDO, Victoria. Complicidad Patronal-militar en la Última Dictadura Argentina: Los Casos de Acindar, Astarsa, Dálmine Siderca, Ford, Ledesma y Mercedes Benz. Revista Engranajes, n. 5, mar. 2006, p. 1-21.

BOHOSLAVSKY, Juan Pablo. Cumplicity of the Lenders. In: BOHOSLAVSKY, Juan Pablo; VERBITSKY, Horácio (Org.). The Economic Accomplices to the Argentine Dictatorship: Outstanding Debts. New York, Cambridge University Press, 2016, p. 105-118.

BUITRAGO, Francisco Leal. La Seguridad Nacional a La Deriva: Del Frente Nacional a La Posguerra Fría. México: Alfaomega, 2002.

BUZAN, Barry; WAEVER, Ole; WILDE, Jaap de. Security: A New Framework for Analysis. London: Lynne Rienner, 1998.

COGGIOLA, Osvaldo. Governos Militares na América Latina. São Paulo: Contexto, 2001. 
COMBLIN, Joseph. A Ideologia da Segurança Nacional: O poder militar na América Latina. 2. ed. Rio de Janeiro: Civilização Brasileira, 1978.

CONADEP. Nunca Más - Informe Conadep - Septiembre de 1984. 1984. Disponível em:

<http:// www.desaparecidos.org/nuncamas/web/investig/articulo/nuncamas/nm as0001.htm>. Acesso em: 20 fev. 2018.

COUTO E SILVA, Golbery. Geopolítica do Brasil. Rio de Janeiro: Livraria José Olympio, 1967.

CRENZEL, Emilio. Entre la Historia y la Memoria. A 40 años del Golpe de Estado en la Argentina. História: Questões e Debates, Curitiba, v. 64, n. 2, p. 36-69, 2016.

DANDAN, Alejandra. The National Securities Commision and the Assault on "Economic Subversion". In: BOHOSLAVSKY, Juan Pablo; VERBITSKY, Horácio (Org.). The Economic Accomplices to the Argentine Dictatorship: Outstanding Debts. New York, Cambridge University Press, 2016, p. 277-291.

DANDAN, Alejandra; FRANZKI, Hannah. Between Historical Analysis and Legal Responsibility: The Ledesma Case. In: BOHOSLAVSKY, Juan Pablo; VERBITSKY, Horácio (Org.). The Economic Accomplices to the Argentine Dictatorship: Outstanding Debts. New York, Cambridge University Press, 2016, p. 186-200.

DELGADO, Frederico. Organized Pillaging. In: BOHOSLAVSKY, Juan Pablo; VERBITSKY, Horácio (Org.). The Economic Accomplices to the Argentine Dictatorship: Outstanding Debts. New York, Cambridge University Press, 2016, p. 269-276.

DUHALDE, Eduardo L. El Estado Terrorista Argentino. Buenos Aires: Colihue: 2013.

FERREIRA, Luciano Vaz. A Securitização da Cooperação para o Controle de Fronteiras da União Européia. LeX Humana, Petrópolis, v. 3, p. 40-58, 2011.

FILIPPINI, Leonardo; CAVANA, Agustín. Responsabilidade Empresarial e Terrorismo de Estado na Argentina. Revista Anistia Política e Justiça de Transição, Brasília, n. 6, p. 316-350, jul./ dez. 2011.

GUALDE, Andrea. The Papel Prensa Case: Notes for a Study. In: BOHOSLAVSKY, Juan Pablo; VERBITSKY, Horácio (Org.). The Economic Accomplices to the Argentine Dictatorship: Outstanding Debts. New York, Cambridge University Press, 2016, p. 292-305.

HEREDIA, Mariana. Economic Ideas and Power During the Dictatorship. In: BOHOSLAVSKY, Juan Pablo; VERBITSKY, Horácio (Org). The Economic Accomplices to the Argentine Dictatorship: Outstanding Debts. NewYork, Cambridge University Press, 2016, p. 47-60.

KENNAN, George. The Sources of Soviet Conduct. Foreign Affairs, New York, v. 25, 
34 | InterAção

566-582, 1947.

KLEIN, Naomi. The Shock Doctrine: The Rise of Disaster Capitalism. New York: Metropolitan Books, 2007.

LORETI, Damián. The Media: Unifed Discourse and Business Deals under Cover of State Terrorism. In: BOHOSLAVSKY, Juan Pablo; VERBITSKY, Horácio (Org.). The Economic Accomplices to the Argentine Dictatorship: Outstanding Debts. New York, Cambridge University Press, 2016, p. 307-322.

PAULÓN, Victorio. Acindar and Techint: Extreme Militarization of Labor Relations. In: BOHOSLAVSKY, Juan Pablo; VERBITSKY, Horácio (Org.). The Economic Accomplices to the Argentine Dictatorship: Outstanding Debts. New York, Cambridge University Press, 2016, p. 175-185.

PAYNE, Leigh A; PEREIRA, Gabriel. Accountability for Corporate Complicity in Human Rights Violations: Argentina's Transitional Justice Innovation? BOHOSLAVSKY, Juan Pablo; VERBITSKY, Horácio (Org.). The Economic Accomplices to the Argentine Dictatorship: Outstanding Debts. New York, Cambridge University Press, 2016, p. 29-46.

QUINTANA, Tomás Ojea; BASUALDO, Victoria; VARSKY, Carolina. The Cases of Ford and Mercedes Benz. BOHOSLAVSKY, Juan Pablo; VERBITSKY, Horácio (Org.). The Economic Accomplices to the Argentine Dictatorship: Outstanding Debts. New York, Cambridge University Press, 2016, p. 159-173.

RAMPINELLI, Waldir J. O Terrorismo de Estado na Argentina. Rebela: Revista Brasileira de Estudos Latino-Americanos, Florianópolis, v. 1, n. 3, p. 356-362, 2012.

RECALDE, Héctor. Suppression of Workers Rights. In: BOHOSLAVSKY, Juan Pablo; VERBITSKY, Horácio (Org.). The Economic Accomplices to the Argentine Dictatorship: Outstanding Debts. New York, Cambridge University Press, 2016, p. 217-234

SCHMITT, Carl. O Conceito de Político, Teoria do Partisan. Belo Horizonte: Del Rey, 2009.

SCHOOL OF AMERICAS WATCH. Acesso em: <http://www.soaw.org>. Disponível em: 20 abr. 2015.

SCHORR, Martín. Industrial Economic Power as Promoter and Beneficiary of Argentina's Refounding Project (1976-1983). In: BOHOSLAVSKY, Juan Pablo; VERBITSKY, Horácio (Org.). The Economic Accomplices to the Argentine Dictatorship: Outstanding Debts. New York, Cambridge University Press, 2016, p. 235-252.

SHARP, Dustin N. Adessing Economic Violence in Times of Transition: Toward a Positive-Peace Paradigm for Transitional Justice. Fordham International Law Journal, San Diego, v. 35, n. 03, p. 780-814, 2012. 
35 | InterAção

TAIANA, Jorge E. Foreign Powers, Economic Support, and Geopolitics. In: BOHOSLAVSKY, Juan Pablo; VERBITSKY, Horácio (Org.). The Economic Accomplices to the Argentine Dictatorship: Outstanding Debts. New York, Cambridge University Press, 2016, p. 61-74.

VIDELA, Jorge. Mensajes Presidenciales: El Proceso de Reorganización Nacional. Disponível em:

<http://www.ruinasdigitales.com/revistas/dictadura/Dictadura\%20\%20Discursos \%20de\%20Videla\%20-\%201976.pdf >. 1976. Acesso em 25 fev. 2018.

WEAVER, Ole. Securitization and Desecuritization. In: LIPSCHUTZ, Ronnie. On

Security: Columbia University Press: New York, 1995, p. 46-86. 